\title{
TWO CASES OF ACTINOMYCOSIS BOVIS SUCCESSFULLY TREATED.
}

By G. H. Gibbings, M.R.C.V.S., Tavistock.

CASE I.-On 24th August I was requested to visit a bullock $2 \frac{1}{2}$ years old, reported to have some obscure affection of the mouth.

The animal had been purchased in the beginning of June for the purpose of being fattened. For the last fortnight he had been losing flesh and had ceased to lick the coat, and there was dribbling of saliva from the mouth. Mastication and deglutition appeared to be painful and performed with difficulty.

I examined the tongue and, as I anticipated, found that it was affected with actinomycosis; the posterior portion of the organ was more particularly diseased, the swelling being distinctly perceptible externally.

A biniodide of mercury blister was applied to the throat, etc., and pot. iodid. ( $3 \mathrm{drs}$.) administered once a day before food.

At the end of a week the owner observed an improvement. The treatment was continued for 9 successive days, when I visited the patient, and found him considerably better; he was feeding well and ruminating, and the skin showed evidence of being licked.

The medicine was now given on alternate days until 6 more doses had been administered, when the owner reported the bullock to have completely recovered. He was ultimately sold to the butcher fat in November.

CASE II.-Eight-years-old cow, in calf. Much resembled preceding, but was observed amiss at least a month prior to my visit on November 3. There was also an enlargement to the extent of a small hen's egg in the left parotideal region. Precisely the same treatment was adopted, with even more gratifying results, as only I 2 doses were administered before a cure was effected. I saw the owner on December I6, and he stated that there was no indication of a reappearance of the disease, and that the cow was in perfect health.

It may be argued that sufficient time has not yet elapsed to warrant the assumption that the latter case is permanently cured, but I have briefly narrated the facts, and leave your readers to draw their own conclusions as to the efficacy of the treatment adopted.

I may add that I was induced to try the action of pot. iodid. in this disease through an account in your quarterly Journal of a series of cascs treated successfully by this agent on the Continent. 